Spatial Demography 2013 1(2): 146-161

http://spatialdemography.org

OPEN ACCESS

via Creative Commons 3.0

\title{
RESEARCH
}

\section{A 3D Spatio-Temporal Geovisualization of Subcounty Estimates of Historic Housing Density in Metro Atlanta, 1940-2009}

\author{
Mathew Hauera \\ a The University of Georgia
}

\begin{abstract}
This paper is a 3D Geovisualization of subcounty estimates of historic housing density in the 20county metro Atlanta Region for 1940-2009 using the Hammer Method. Representing information spatially and temporally, by themselves, are well developed techniques for demographers to use. Representing information spatio-temporally, together, however, is underdeveloped in the demographic literature. This paper includes a number of contemporary geovisualization techniques that can be employed to better visually represent demographic data in a more intuitive manner. Policymakers and other consumers of demographic data could greatly benefit from improved representations of the spatio-temporal data that demographers produce.
\end{abstract}

KEYWORDS: Population estimates, geovisualization, 3D, spatio-temporal, Hammer method

\section{INTRODUCTION}

Maps provide a sufficient ability to visually represent the world we live in and are immensely popular outside of the academy (Kraak 2006). This is largely due to the generally accepted definition of a map as being defined by its use. The cartographic literature is replete with textbooks and articles on map making (see Goodchild, 2010 for more). But the ability to represent both space and time is not nearly as developed. This "precision metric" problem of representing both space and time on the same

Corresponding Author: Mathew Hauer, Public Service Assistant, Governmental Services and Research, Carl Vinson Institue of Government, The University of Georgia, 201 N. Milledge Ave, Athens, GA 30602

E-mail: hauer@uga.edu map is something cartographers have been trying to solve.

Many efforts have been made to create better ways of representing spatio-temporal data in other geographic disciplines. Andrienko et al (2010) used self-ogranizing maps to try and better represent spatio-temporal phenomena. Bell et al (2000) tried using Virtual Reality Modeling Language (VRML) to enhance the representation of population projections in small areas. Mei Po Kwan has published numerous articles on space-time aquariums (Kwan 2003). Dorling and Openshaw (1992) made a call for animated maps for representing population change over time. These advances are largely based upon the computer science and geographic literature; the demographic literature sparsely addresses these issues despite demographic research sitting squarely within the realm of 
Figure 1. Housing growth Clusters for 1940-1990 (Hammer et al 2004).

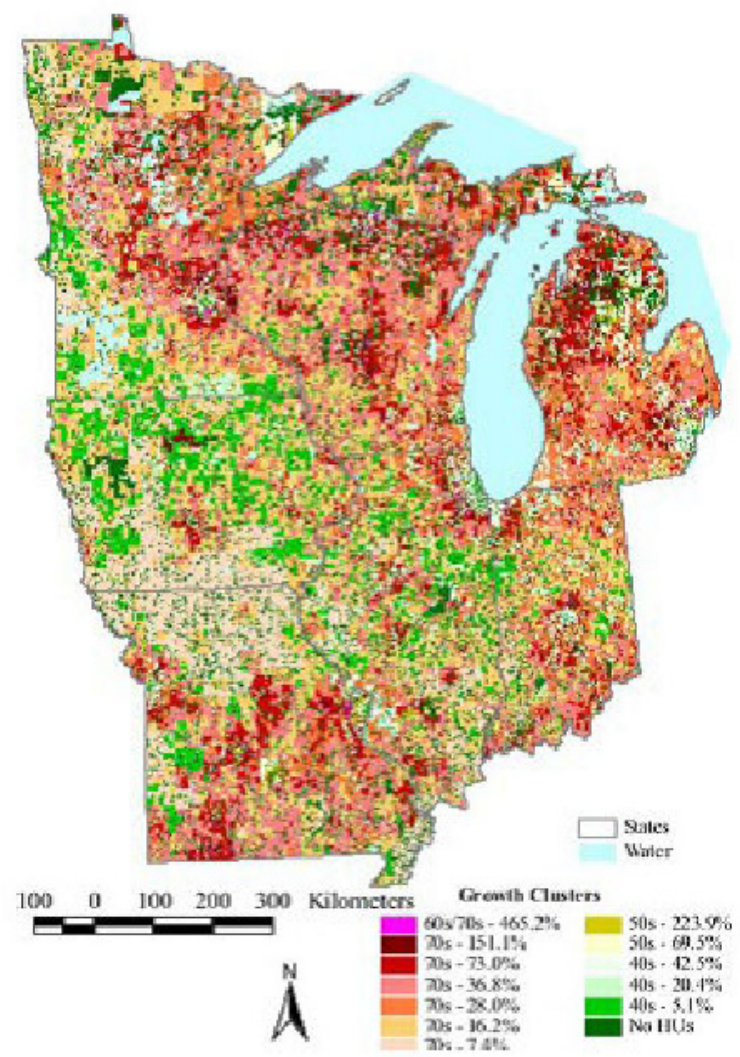

Fig. 11. Housing growth clusters, 1940-1990, North Cental Region.

spatio-temporal phenomena ${ }^{1}$. Additionally, many of these approaches fail to create a simple, cohesive approach for representing spatiotemporal demographic data.

Although cartography and demography have a long history together (Voss 2007), techniques do not flow as freely between the disciplines as much as they should. Consequently, demographic maps do not represent spatio-temporal data efficiently. This is due to several issues inherent to demography that problematize cartographic representation. First, population data is collected in a wide range of geographies that are generally located within a nested hierarchy. The

1 Natalia Andrienko et al published a catalogue and analysis of spatio-temporal visualizations in 2003.

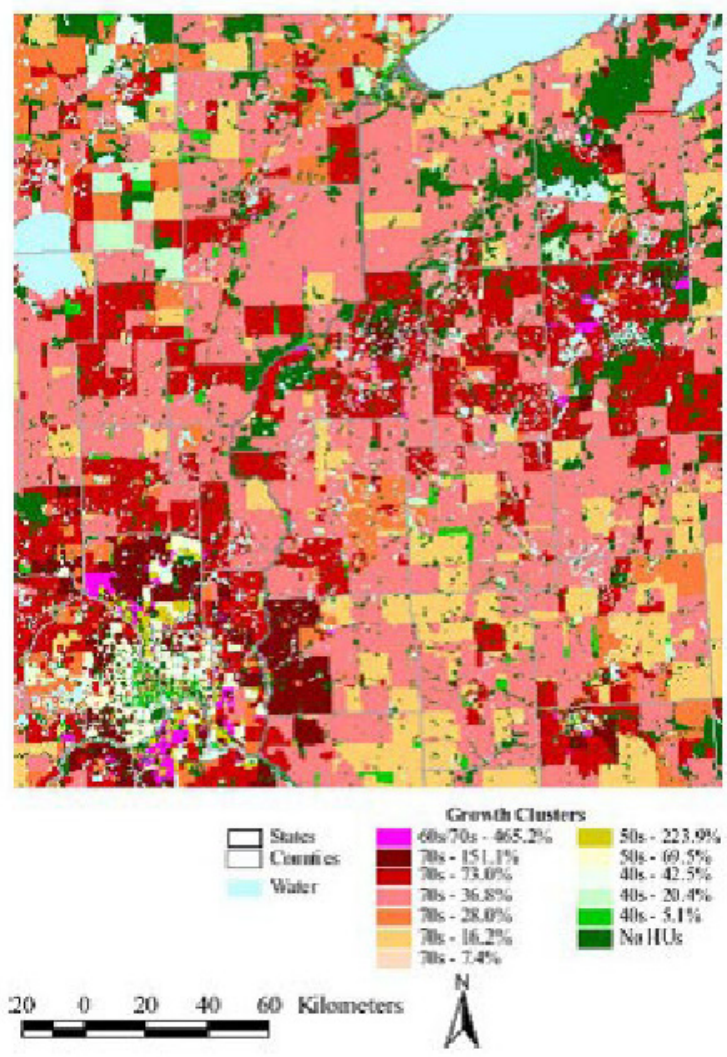

Fig. 12. Housing gronth clusters, 1940-1990, Twin Cities, MN and survounding area.

granularization of this data allows for robust geographical analysis but poses problems when trying to represent these geographies outside of their respective scales. For instance, representing population data of block groups across several states in a single map requires tens of thousands of areal units to be displayed. Furthermore, not all areal units are created equal; the land area that any areal unit occupies is based on the population in that areal unit. This poses problems in accurately reflecting small area geographies because the smaller the geography, the more people that live in that geography. Demographers have seemingly ignored the issues of scale (see Hammer et al 2004 and the Exurban Change Project 2003 for example) choosing to represent small geographies across large areas. 
Figure 2. Population Projections of London 2011-2030 (Cheshire 2011).

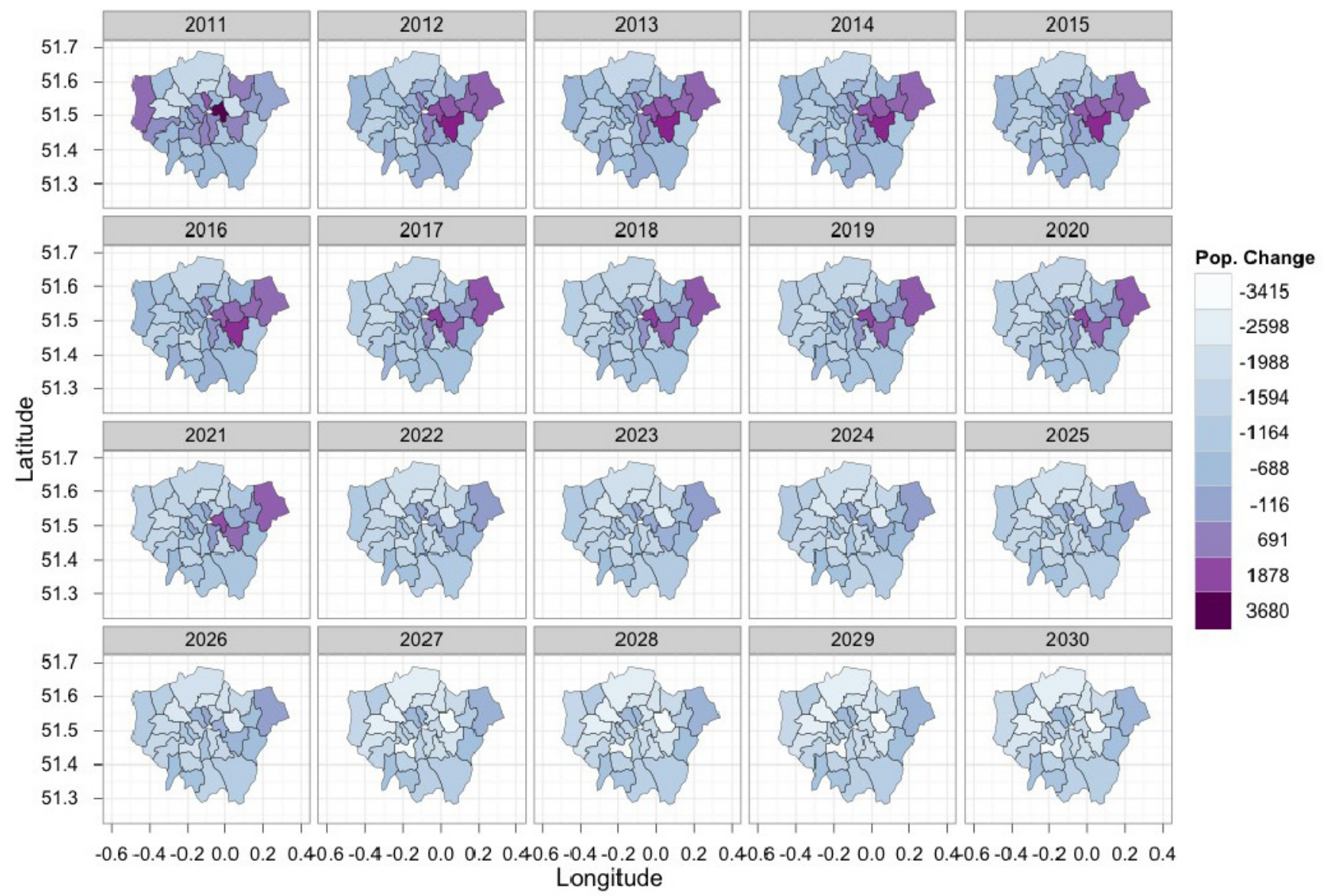

Second, population data is collected over multiple time periods and situating demographic information within its temporal contexts is very important for demographers. In the United States, detailed digital population data is available for over 100 years of time. While graphically displaying temporal data in a table is the de facto method of delivering demographic data, there is no efficient method for graphically displaying temporal population data geographically. Traditionally demographers have approached this problem with two solutions. One is to simplify change over time into a single category and proceed with mapping and the other is to sequentially produce maps of the same space to show temporal change across several maps.

Third, simple chloroplethic mapping further compounds this problem, as David Martin has noted (1989). Change within categories is thus ignored by the nature of the categorization itself. Some demographic work is beginning to address the problems of chlorpolethic maps with some 3D maps beginning to be published, but the volume is small and the use of the $\mathrm{z}$-axis poses problems unto itself.

This paper will discuss published demographic maps to highlight the shortcomings of current methods within spatial demography for the representation of spatio-temporal population data. It will also demonstrate contemporary cartographic techniques that can be employed to help solve the issues that naturally arise in the mapping of population data.

\section{Current Issues}

Figure 1 shows a classic example of a 
Figure 3. Population Change for Ohio Townships 1970-2000 (Exurban Change Project 2003).
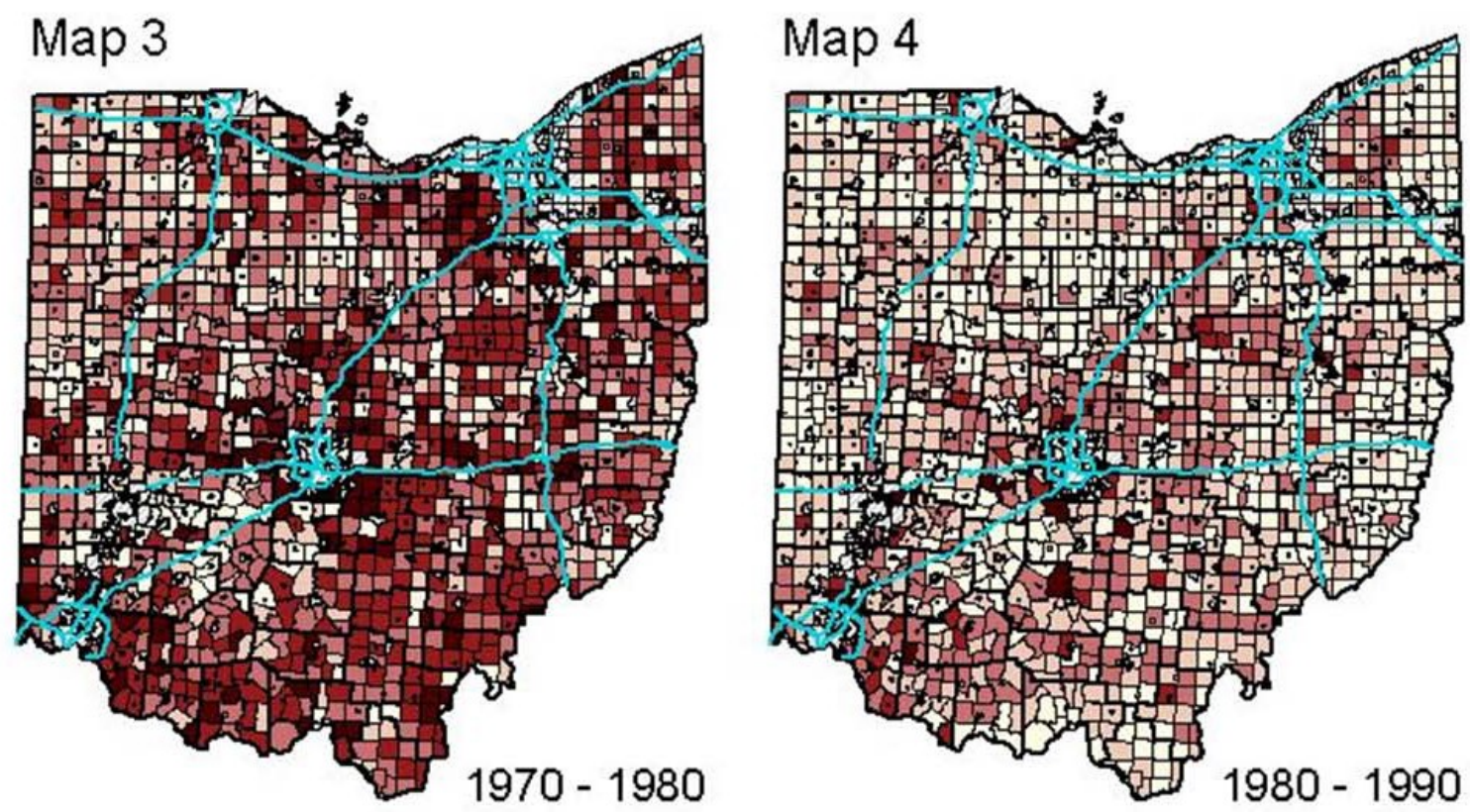

Maps 3 - 5: Ohio Township Population Change 1970 through 2000 by Decade
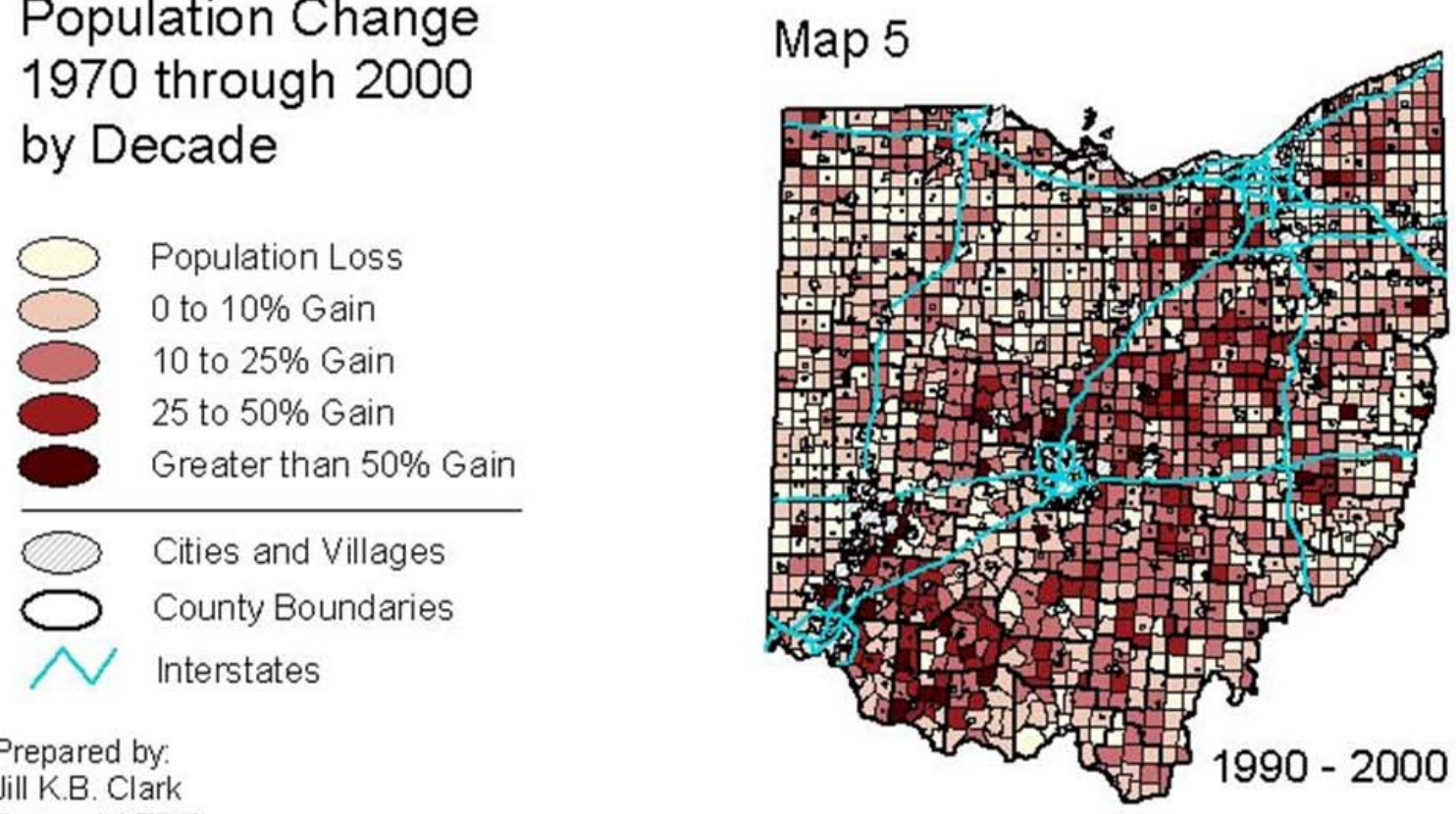

Prepared by. Jill K.B. Clark Dept. of AEDE

Ohio State University 1.27 .03 
Figure 4. Population Growth Trends 1970-2030 for US Counties (National Assessment Synthesis Team 2004).

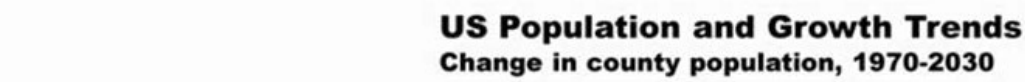

Projected change in county population (percent), 1970 to 2030

\begin{tabular}{|l}
\hline \\
\hline$+250 \%$ (highest $+3,877 \%$ ) \\
$+50 \%$ to $+250 \%$ \\
$+5 \%$ to $+50 \%$ \\
$-5 \%$ to $+5 \%$ \\
$-20 \%$ to $-5 \%$ \\
$-40 \%$ to $-20 \%$ \\
$<-40 \%$ (lowest $-60 \%$ )
\end{tabular}

Each block on the map illustrates one county in the US. The height of each block is proportional to that county's population density in the year 2000 , so the volume of the block is proportional to the county's total population. The color of each block shows the county's projected change in population between 1970 and 2030 , with shades of orange denoting increases and blue denoting decreases. The patterns of recent population change, with growth concentrated along the coasts, in cities, and in the South and West, are projected to continue.

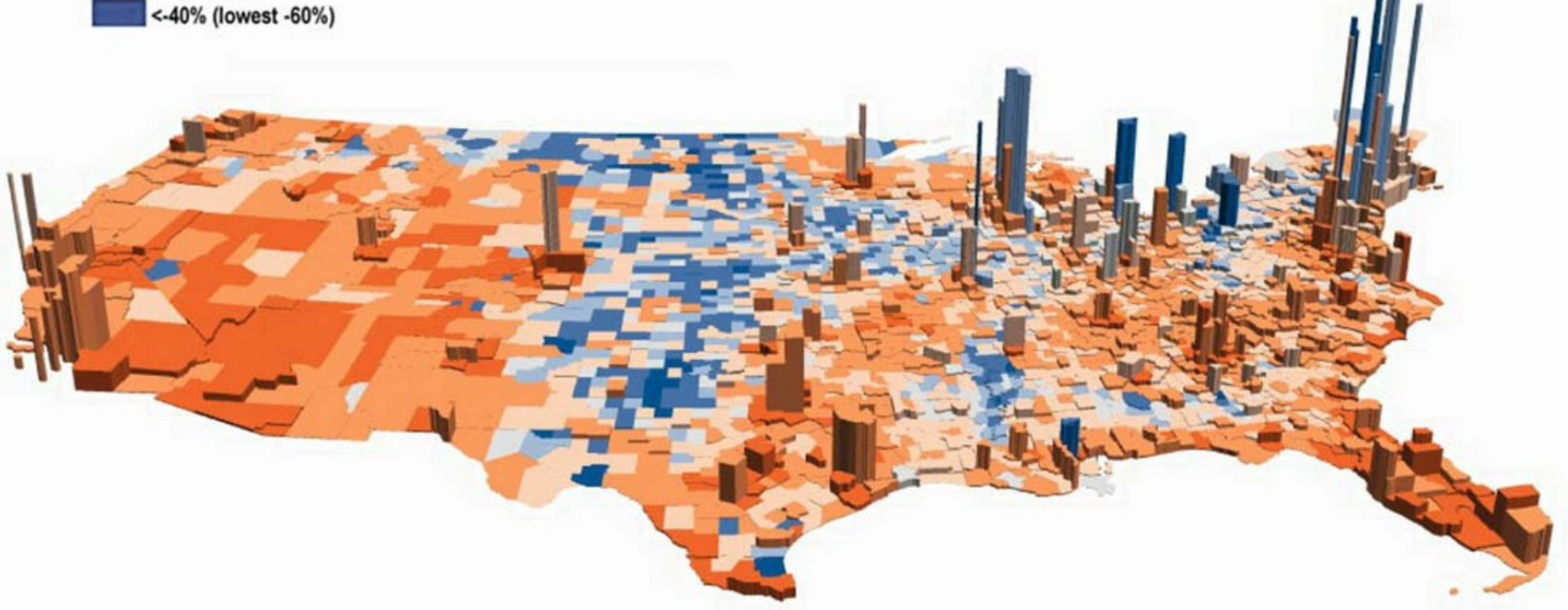

demographer's approach to mapping. In this example, Hammer et al. (2004) have clustered geographic units both by characteristic (growth rate) and time (when did the growth rate occur). In this sense, they are displaying where $\rightarrow$ what and when, to borrow from Andrienko et al's spatio-temporal framework (2003).

While this clustering is useful for their purposes of projecting housing units, this characterization assumes that clustering characteristics temporally can only occur within one time period; that units clustered in one growth category in one time period are not clustered in another growth category in another time period. Condensing fifty years' worth of housing change into a single cluster that can be displayed onto a single map demonstrates the limitations with this method for spatio-temporal phenomena. This approach to spatio-temporal phenomana is not necessarily applicable for all a demographer's needs.

Another way demographers attempt to represent spatio-temporal data is through the use of multiple maps, each map representing a point in time. Recognizing the spatial patterns of population change with a few maps can be easy with this approach. But if the timescale gets larger, or the scale on the map itself gets smaller, trying to visually interpret the spatio-temporal information becomes very confusing. Figure 2 shows how confusing this can become.

In this figure, population projections for London are presented annually for 2011-2030. Temporal scaling increasingly becomes a problem as the time horizon increases, as figure 2 shows. To visually distinguish patterns of change through an array of twenty maps is very problematic and 
destroys any sort of visual continuity. While this method succeeds in providing detailed data on projected population change in London, the increasing complexity associated with longer time scales causes serious problems with this approach. In highly detailed temporal maps, there is often more data than information.

Just as temporal scaling causes issues, so does geographic scale. The larger the number of areal units that are displayed, the more difficult it is to distinguish patterns. Both Figures 1 and 3 show how visually complicated large numbers of geographic units can be. Figure 3 maps population change for Townships in Ohio for 1970 to 2000.

The nested geographies within these set of maps makes it very difficult to distinguish the boundaries between either cities or counties. The amount of data that is presented in these two sets of maps is simply overwhelming.

Representing space through time with simple chloroplethic mapping further compounds this problem, as David Martin noted (1989). Change within categories is thus ignored by the nature of the categorization itself. This can be rectified through the use of $3 \mathrm{D}$ mapping and geovisualization techniques. Figure 4 shows an attempt at representing spatio-temporal change through a $3 \mathrm{D}$ visualization. While this approach is better, it still demonstrates the shortcomings of representing change as a summary between two time periods. And since the data is represented on the z-axis, seeing the data behind high peaks becomes troublesome. For instance, seeing the population change in Maine is nearly impossible with this map due to the high peaks created with the large amount of population change that is taking place in New York. But it doesn't take peaks that large to still cause visual problems. The Upper Peninsula of Michigan and the areas between Los Angeles and San Francisco also experience visual problems. Trying to see the population change behind the peaks is problematic in $3 \mathrm{D}$ maps.

Furthermore, the space that areal units occupy on the map is not constant. Some areal units are larger than other areal units and thus appear to be more important simply due to size. Trying to make visual comparisons between areal units of different sizes with different growth rates over different time periods is problematic and complicated to say the least. For much of population data, the larger the areal unit is the smaller the population is. Areal units that occupy the greatest space on a map are generally the areal units with the least populations. Controlling for the size of areal units would help alleviate this issue. Representing densities instead of the total amount of population is an alternative solution.

The geographic literature has long dealt with these problems of temporal variation through space and spatial variation through time (Adrienko, et al. 2010). Typically spatial representations of temporal events are represented sequentially to aid the user in perceiving space through time (Slocum 1999). By placing many still images on a simple page, or series of pages, changes in space and time can be difficult to perceive (Dorling and Openshaw 1992). While the jury is mostly out with regards to the most effective visualization technique, Kraak and Ormeling (2003) demonstrate the advantages of animation, Kim et al. (2007) show that animations are not as effective as graphs, and Dorling and Openshaw (1992) argue too much information in animations makes comparisons difficult. Recently a robust analysis comparing static, animated, and space-time cubes concluded that animated maps are the best way to represent moving objects (Biadgilgn, Blok and Huisman 2011). Naturally displaying movement with the use of movement would yield the best representation.

This paper will use the Hammer method (Hammer, et al. 2004) to demonstrate the use of modern cartographic techniques for representing spatio-temporal demographic data, specifically aiming to mitigate the drawbacks outlined above in representing spatio-temporal demographic data. The Hammer Method provides an excellent approach to illustrate this point because the resultant historical estimation is along a large time scale (70 years) and a large geographic scale (census block groups) while introducing 
geographers to a demographic method that can be used to attempt to correct for the Modifiable Areal Unit Problem (MAUP) ${ }^{2}$.

\section{METHODS}

\section{Hammer Method}

Hammer et al. (2004) has developed a method to work around the MAUP and to produce historic population estimates in consistent geographies for sub-county areas (in essence a "backcast"). The Hammer Method is based on historic estimations of the housing stock at the smallest geography possible, the block group, based on the "year structure built" question in Census data. Thus we are able to immediately produce estimates, by decade, of the number of housing units in the most contemporary boundaries. While boundaries change, a house does not move.

\section{Data sources}

The data required to conduct the Hammer Method come from two main sources. The first source of data comes from the American Community Survey 2005-2009 estimates. The 2005-2009 ACS data gives us the "year structure built" data as well as the contemporary boundaries for block groups. This data is the building block for all estimates and represents the "partial estimate" that needs to be adjusted. While the ACS is not the decennial census, the ACS was intended to mimic the decennial census despite ACS estimates being less precise than previous decennial estimates (Rohanna and Tayman 2006). All released ACS data represents confidence limits above 90\% (Swanson and Tayman 2012).

The second piece of data comes from the Historic

2 The modifiable areal unit problem (MAUP, Martin 1989) has plagued geographers and demographers for a long time. Being able to produce accurate data when boundaries are constantly shifting is incredibly difficult. In the United States, the decennial census is one of only a few sources of historic population data. County boundaries are mostly static, but sub-county areas are redrawn with every new census. count from each census in the backcast. Data for the historic count from each census comes from digitized records available on the Census Bureau's website ${ }^{3}$.

\section{Housing unit adjustment methods}

Utilizing only the "year structure built" question would lead to an underestimate or partial estimate of the housing units present in any historical period. While housing units do not "move" there can be conversions and demolitions. These changes to the housing stock must be accounted for and the partial estimates must be adjusted. First, we must adjust the partial estimate of the housing units in the block group.

The Housing Units in each block group built before 1939 must be adjusted to the county level counts of housing units from the 1940 census. To do this, the number of housing units built before 1939 in each block is divided by the sum of all housing units in the county built before 1939 to create the proportion of housing units in each block group. This proportion is then multiplied by the total number of housing units counted in the 1940 census to produce the adjusted number of housing units in a block group for 1940 .

$$
\hat{H}_{i j}^{t}=\left(\frac{H_{i j}^{t}}{H_{j}^{t}}\right) * H_{j}^{T}
$$

$\hat{H}_{i j}^{t}=$ Adjusted Housing Units in Block Group $i$ in County $j$ in Time $t$

$H_{i j}^{t}=$ Housing Units in Block Group $i$ in County $j$ in Time $t$

$H_{j}{ }_{j}=$ Housing Units in County $j$ in Time $t$

$H^{T}{ }_{j}=$ Housing Units in County $j$ in Time $T$

Where the Adjusted Housing Units in Block Group $i$ in county $j$ in time $t$ (1940) is equal to the number of housing units built in block group $i$ in county $j$ in time $t$, as measured in the ACS,

3 For 1940-1990, data can be found at http://www.census.gov/prod/cen199o/cph2/cph-2-11.pdf. For Data for 2000, data is available at American Fact Finder. 
Figure 5. Atlanta Housing Density, 1940.

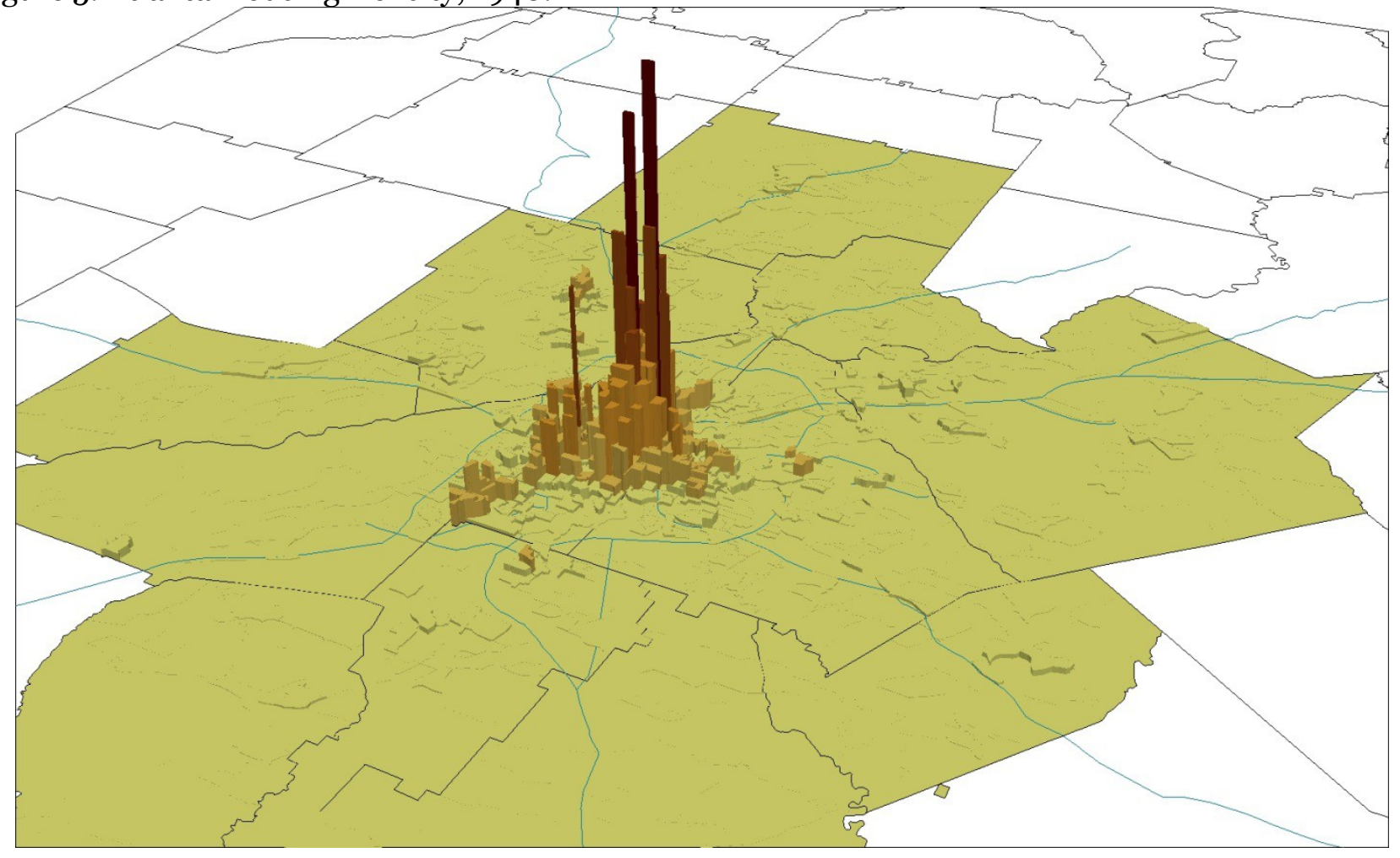

divided by the housing units in county $j$ in time $t$, as measured in the ACS as well, multiplied by the housing units in county $j$ as recorded in time $T$, the census counts for the decade in question.

This amounts to the Adjusted Housing Units in any given block being the ratio of a block group's housing units to the total housing units in a county for the given decade multiplied by the county's housing units as enumerated in the actual decade in question.

Once the adjusted housing units for the initial year, 1940, are calculated, the number of housing units in proceeding time period, 1950 in this case, can be estimated.

$$
\hat{H}_{i j}^{t+10}=\left[\frac{\hat{H}_{i j}^{t}+H_{i j}^{t+10}}{\sum\left(\hat{H}_{i j}^{t}+H_{j}^{t+10}\right)}\right] * H_{j}^{T+10}
$$

Where the Adjusted Housing Units in Block $i$ in county $j$ in time $t+1 O$ (1950) is equal to the estimated adjusted number of housing units in block group $i$ in county $j$ in time $t$ plus the number of housing units built in time $t+1 O$ (1940s in this case) in block group $i$ in county $j$ divided by the sum of housing units built before time $t+1 O$ in county $j$ multiplied by the housing units in county $j$ as recorded in the 1950 census.

The adjusted number of housing units in any given block group within a county for the proceeding time period is a function of adding the number of surviving housing units for the proceeding decade to the adjusted number from the preceding decade, dividing this by the sum of all of the block groups in a given county, and multiplying the resultant ratio by the count of housing units from the actual census from the decade in question.

This process is repeated until the most recent data, in which case no adjustments are needed.

To perform the Hammer Method, data came from the 2005-2009 American Community Survey for all block groups in the 10-county regional 
planning commission. These counties are Cherokee, Clayton, Cobb, DeKalb, Douglas, Fayette, Fulton, Gwinnett, Henry, and Rockdale counties.

All calculations were performed in excel and imported into ArcGIS 10.0 to be mapped, and finally ArcScene 10.0 for the visualization. The total number of housing units in each block group for each time period was divided by the total square miles for each block group to determine housing density for each period. This value was then extruded and multiplied by 10 to represent the density along the z-axis.

Finally, all eight maps were layered on top of each other and animated for the final two animations. This cartographic technique can be accomplished in several ways using only a few steps. For the first animation the steps are as follows:

1) A map displaying each decade's extruded and classified block groups is exported as jpeg image file.

2) The image files were then edited to add a date in the corner (1940 for the first image, 1950 for the second, etc.) so the viewer is not 'lost in time.'

3) The images were then sequentially loaded into a gif making program. For this animation, Ulead Gif Animator 5.0 was used.

4) The timing for each frame to change was adjusted for personal preference. This is the frame rate. For this animation, 2.5 seconds was used.

By holding the viewing angle constant, the viewer is kept in a static location for viewing the space through time. These procedures can be replicated with a moving camera angle through the use of ArcMap's 3D camera functions. The final animation involves a camera that rotates slightly around Atlanta to ensure the viewer has adequate views of all block groups in the region.

\section{DISCUSSION}

Figure 5 shows the first map of Atlanta housing density for 1940. Viewing density of metro Atlanta's housing in a pure $3 \mathrm{D}$ environment as a static map only, the visualization improvements are immediately notable.

There are two animations are accompanying this paper in digital form. The first is $3 \mathrm{D}$ animated geovisualization of housing growth from 19402009 with a static viewing angle. The second simply involves a camera that rotates around downtown Atlanta.

These maps are highly dynamic and immediately demonstrate the power of $3 \mathrm{D}$ geovisualization for demographic data. The $3 \mathrm{D}$ maps provide intuitive, simple, and easy visualization of density and are perfect for demonstrating demographic data to a lay audience. Though there is debate about the effectiveness of geovisualization (), these animations break away from static representations of temporal events.

Though this paper does not delve into the depths of cartographic inquiry, it is important to highlight aspects of the ontological debate about maps.

The Hammer method provides an excellent framework to demonstrate the power of geovisualization for demographic data. It seems that $3 \mathrm{D}$ to most demographers refers to Demography, Development, and Democracy (Adepoju 2006) and not three-dimensional. Instead of producing eight separate maps containing over 1500 data points each, that would require users of the data to have impeccable visual analysis skills, we have created one simple animated map that shows space through time.

The deficiencies discussed earlier in the paper are minimized through this process. Change between periods is not ignored in order to produce a singular map of population change. We are able to accurately see the dynamic housing change that occurs over this period, in each individual period. Had a summary approach been used, seeing the housing density of downtown Atlanta first increase and then begin to shrink over the estimates horizon would not have been possible.

Temporal scaling is minimized since the eye does 
not have to dance between eight static maps. Since the maps are essentially stacked on top of each other and animated, the viewer can quickly and easily see change over time across a very large time scale. Eight separate and distinct time periods are spatially held constant to provide an easier viewing experience.

Geographic scaling is minimized as well since the "busyness" does not interfere with the message of the map. Instead of viewing 1500 block groups in 8 maps, we are viewing 1500 block groups in a single map, eight times.

And finally the problems with $3 \mathrm{D}$ maps creating a virtual landscape that can potentially block information that is located "behind" other information is minimized as well through the use of varying camera angles in the animation. Furthermore, the difference in size between areal units is also controlled for by calculating density instead of relying solely on the housing estimates themselves.

Ultimately, an animated 3D geovisualization of temporal phenomena can be much more easily understood and conveyed in rapid manner. Though these maps do not invite the user to be a part of the landscape itself, they do provide a more inviting viewing experience than the "gods eye" (Kwan, 2002) map.

This method of cartographic consumption, animated $3 \mathrm{D}$ density maps, invites the viewer to visually analyze the map as well. Such analysis yields some surprising aspects of housing change in Atlanta in the post-war period that would go unnoticed if the same data were visualized using static, flat maps.

This animation demonstrates the increasing density of Downtown Atlanta for 1940-1960 followed by the eventual decreasing density in the ensuing periods. This increase then decrease occurs wholly within the same chlorplehtic categories. Without the ability to see the magnitude of a unit's characteristics within a category, a feature inherent in a $3 \mathrm{D}$ map, witnessing any downtown decline, let alone increase, would be difficult. The classic donut shape of modern urban development (Soja 1996) is readily apparent when viewing the maps. However, seeing the increasing density followed by decreasing density that bisects the time period is not an expected phenomenon.

There are a number of other interesting phenomenon that are apparent when viewing these maps in this manner that would have not been apparent had any of the previous visualization techniques that have been criticized in this paper been used. Aside from the rapid decentralization of the city, the duality of increase then decrease of the time period would have been lost.

The rise of edge cities (Garreau 1992) would have appeared abruptly and rapidly. It is clear that the edge cities only sprang up in the 1980s and have seen slower and slower growth from their initial creation. Furthermore, the rise of some of the edge cities is very apparently overstated with Buckhead, just north of the central business district, being a prime example where density is not as high as the density surrounding Doraville, a small community just northeast of downtown.

Second, without the moving camera angles, seeing the growth that exists in Marietta, far to the northwest of downtown, and areas northwest of downtown Atlanta would have been partially blocked, at least, by the size of downtown density. Understanding the growth along the I-75 corridor, which runs from southeast to northwest, is a very important aspect of the growth that's occurred in Atlanta over the last half-century.

Spatio-temporal data also have a dual problem. First, representing dynamic movement (as characterized by change over time) through a static medium (that of a flat map) creates a disconnect between the information and the consumption of the information. The ontology of movement dictates that the representation of movement be in motion. Otherwise the representation of movement is further removed than it needs to be from the reality of movement.

Second, the paradigm of cartography is that of 
the static, flat map. To represent a dynamic essence in a dynamic form requires consumption to in a digital format, yet most of the world still relies on analog presentation formats. This presents an interesting conundrum since the maps we produce are usually wholly a part of a digital production process. The maps that were produced for this project were wholly created within a digital environment. The shapefiles, computer software, calculations, and animations are all produced digitally. Yet the most common consumption method is still to produce maps for consumption in a paper environment. Though the call to shift to a dynamic paradigm aren't new (Dorling and Openshaw 1992), this paper presents a compelling case for the power of a dynamic map digitally consumed representing dynamic information digitally produced.

The lag between contemporary cartographic techniques and those that demographers and other human geographers employ is probably partly due to trying to rectify this issue of production and consumption differences with dynamic information and static representation.

\section{CONCLUSION}

Demographic data represents an ample opportunity to incorporate $3 \mathrm{D}$ geovisualization techniques developed for other sciences into human geographic endeavors. Demographic techniques such as the Hammer Method (2004) produce excellent spatio-temporal demographic data that can greatly benefit from $3 \mathrm{D}$ geovisualizations.

3D demographic maps can still be improved, however. Incorporating legends into the maps could further enrich the data and could be strategically placed so as to not interfere with the animation. Digital consumption of the dynamic animated maps is also a necessity, incorporating these methods into a paper report or paper would be nearly impossible.

In addition, this method lends itself to being used for counts or totals instead of for percentages. And creating a map that is a "summary" of demographic data is also problematic. Despite these shortcomings and areas for improvements, $3 \mathrm{D}$ geovisualization can create incredibly rich and intuitive demographic maps.

For the study of Demography, a 3D geovisualization, even one with just spatial data, creates a visual experience of population that Edward Tufte would call "Beautiful Evidence" (2006) and demonstrates that the study of population is an ample candidate for modern cartographic techniques. By moving visualization techniques developed by cartographers and geographic technicians from 'harder' approaches such as tropical cyclone behavior (Gienko and Terry 2012) or seismic activities (Salom, et al. 2009) to 'softer' approaches such as the one presented in this paper, geovisualizations can be appreciated and produced by a wider audience. Policy makers and the public writ large can benefit from seeing maps of the world they occupy in a rich and intuitive manner.

\section{References}

Adepoju, Aderanti. "Placing International Migration in the Context of the 3D's: Demography, Development, and Democracy." International Migration 44 (2006): 3-13.

Adrienko, G., et al. "Space-in-Time and Time-in-Space Self-Organizing Maps for Exploring Spatiotemporal Patterns." Computer Graphics Forum 29 (2010): 913922.

Andrienko, Natalia, Gennady Andrienko, and Peter Gatalsky. "Exploratory Spatio-Temporal Visualization: an Analytical Review." Journal of Visual Languages and Computing 14 (2003): 503-541.

Bell, M., C. Dean, and M. Blake. "Forecasting the pattern of urban growth with PUP: a web-based model interfaced with GIS and 3D animation." Computers, Environment and Urban Systems 24, no. 6 (2000): 559-581.

Biadgilgn, D.M., C.A. Blok, and O. Huisman. "Assessing the Cartographic Visualization of Moving Objects." Momona Ethiopian Journal of Science 3, no. 1 (2011): 80-104. 
Cheshire, James. Spatial Analysis.co.uk. February 16, 2011. http://spatialanalysis.co.uk/2011/o2/mappinglondons-population-change-2011-2030/ (accessed November 2011).

Dorling, Danny, and S. Openshaw. "Using Computer Animation to visualize space-time patterns." Environment and Planning B: Planning and Design 19 (1992): 639-650.

Garreau, Joel. Edge City. Anchor, 1992.

Gienko, Gennady, and James Terry. "Geovisualiation of Tropical Cyclone Behaviour in the South Pacific." Geological Society, 2012: 195-208.

Goodchild, Michael. "Twenty Years of Progress: GIScience in 2010." Journal of Spatial Information Science, no. 1 (2010): 3-20.

Hammer, R., S. Stewart, R. Winkler, V. Radeloff, and P. Voss. "Characterizing dynamic spatial and temporal residential density patterns from 1940-1990 across the North Central United States." Landscape and Urban Planning 69 (2004): 183-199.

Kim, S., M. Yoon, S. M. Whang, B. Tversky, and J.B. Morrison. "The Effect of Animation on Comprehension and Interest." Journal of Computer Assisted Learning 23, no. 3 (2007): 260-270.

Kraak, Menno-Jan. "Why Maps Matter in GIScience." The Cartographic Journal 43, no. 1 (2006): 82-89.

Kraak, Menno-Jan, and Ferjan Ormeling. Carography: Visualization of Spatial Data. Prentice Hall, 2003.

Kwan, Mei-Po. "Feminist Visualization: Reenvisioning GIS as a Method in Feminist Geographic Research." Annals of the Association of American Geographers 92, no. 4 (2002): 645-661.

Kwan, Mei-Po, and Jiyeong Lee. "Geovisualization of Human Activity Patterns Using 3D GIS: A TimeGeographic Approach." In Spatially Integrated Social Science: Examples in Best Practice, by Michael Goodchild and Donald Janelle. Oxford: Oxford University Press, 2003.

Martin, David. "Mapping Population Data from Zone Centroid Locations." Transactions of the Institute of British Geographers 14, no. 1 (1989): 90-97.

National Assessment Synthesis Team. Overview: Our
Changing Nation. 2000. http://www.usgcrp.gov/ usgcrp/Library/nationalassessment/overviewChangin gNation.htm (accessed November 2011).

Rohanna, Kristen, and Jeff Tayman. "Census Data for Transportation Planning, Analysis, and Implementation." Journal of Economic and Social Measurement 31 (2006): 167-183.

Salom, Pierre, Remi Megret, Marc Donias, and Yannick Berthoumieu. "Dynamic Picking System for 3D Seismic Data: Design and Evaluation." International Journal of Human-Computer Studies 67, no. 7 (2009): 551-56o.

Slocum, Terry. Thematic Cartography and Visualization. Upper Saddle River: Prentice Hall, 1999.

Soja, Edward. Thirdspace. Cambridge: Blackwell, 1996.

Swanson, David, and Jeff Tayman. Subnational Population Esimates. Springer, 2012.

The Exurban Change Project. The Exurban Change Project. January 27, 2003. http://aede.ag.ohiostate.edu/programs/exurbs/growthandchange/maps \%203_5.jpg (accessed November 2011).

Tufte, Edward. Beautiful Evidence. Cheshire, Connecticut: Graphics Press LLC, 2006.

Voss, P. "Demography as a Spatial Social Science." Population Research and Policy Review 26 (2007): 457-476.

\section{Declaration of Conflicting Interests}

The author declared no potential conflicts of interest with respect to the research, authorship, and/or publication of this article. 


\section{Appendix}

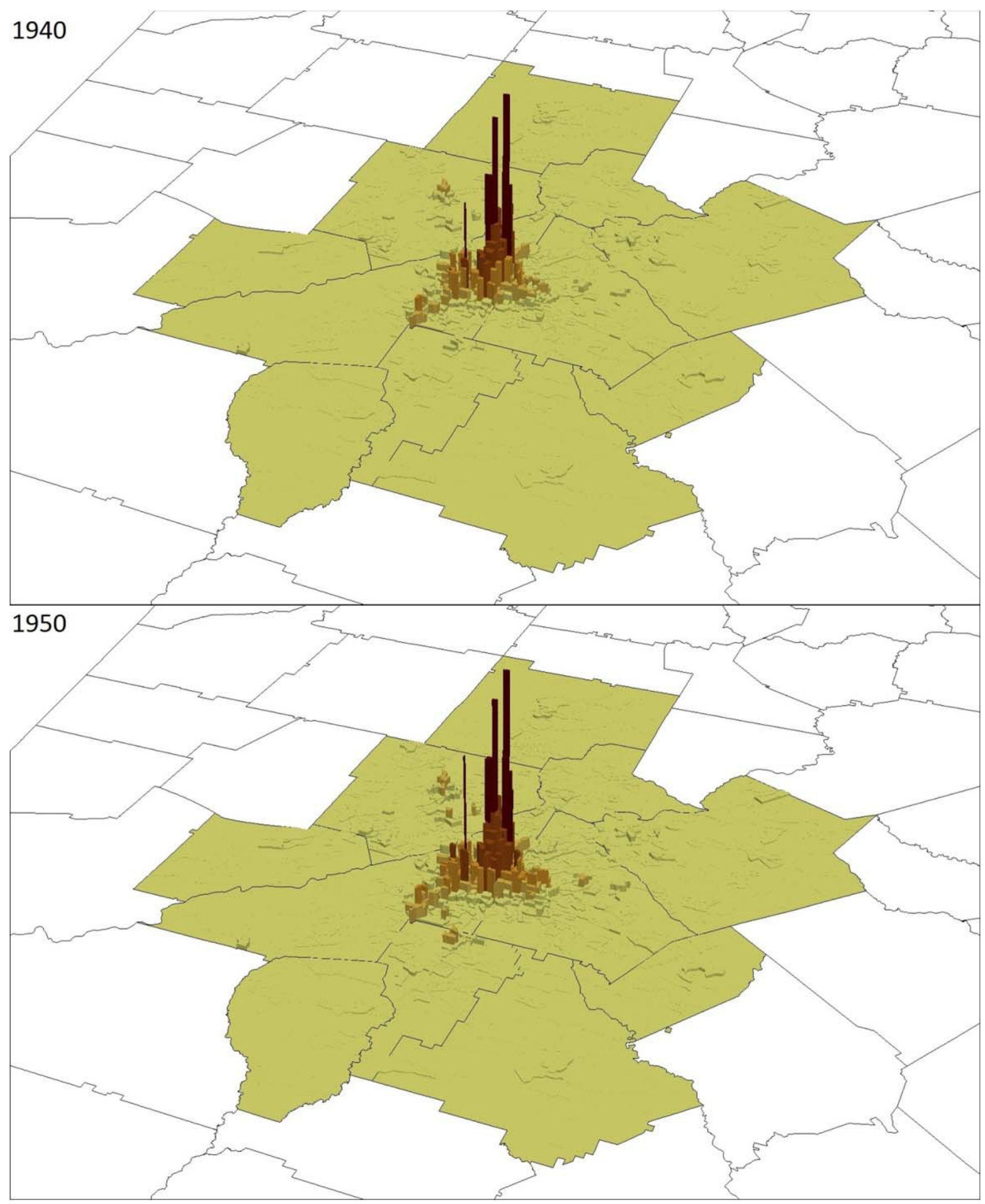




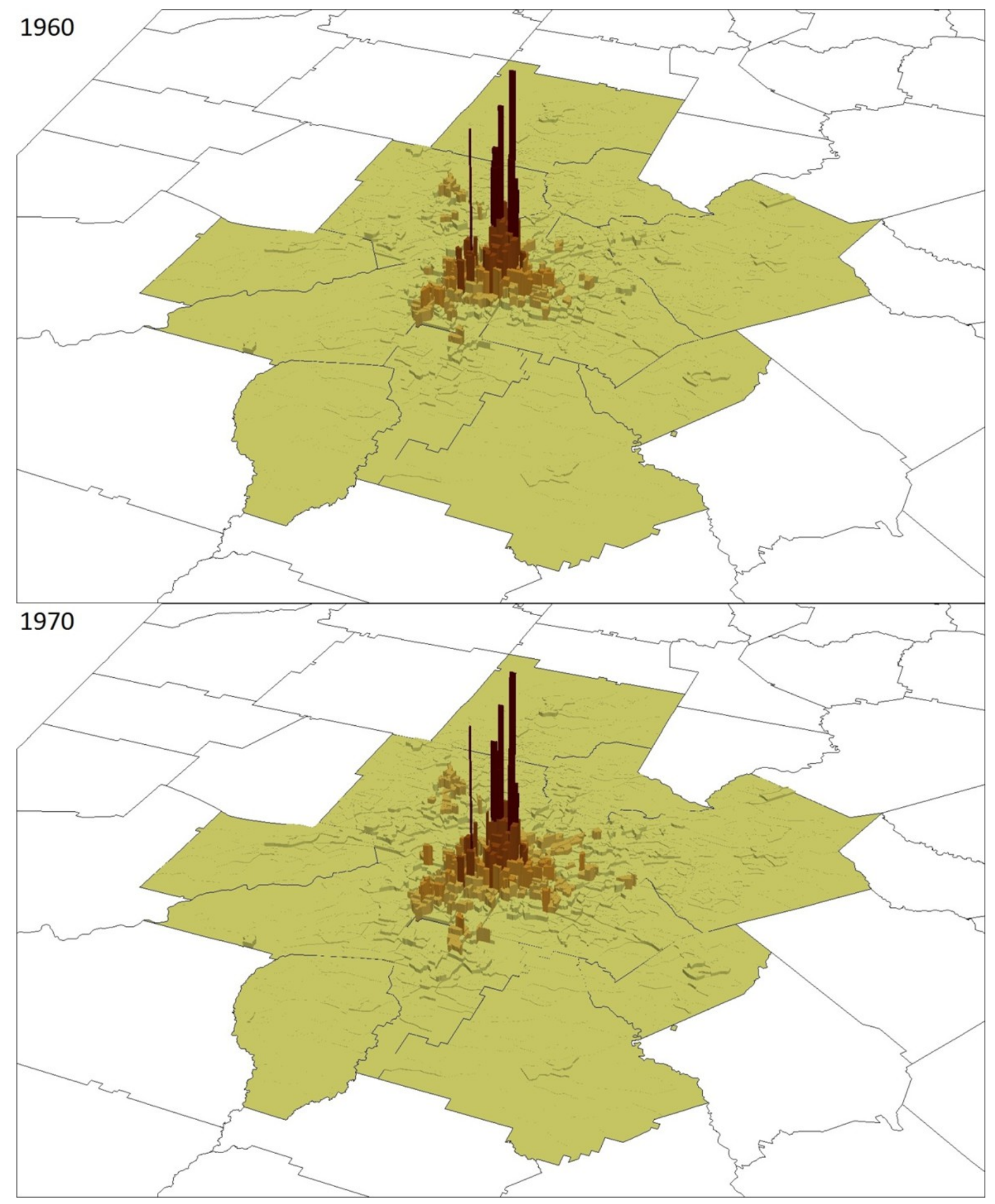




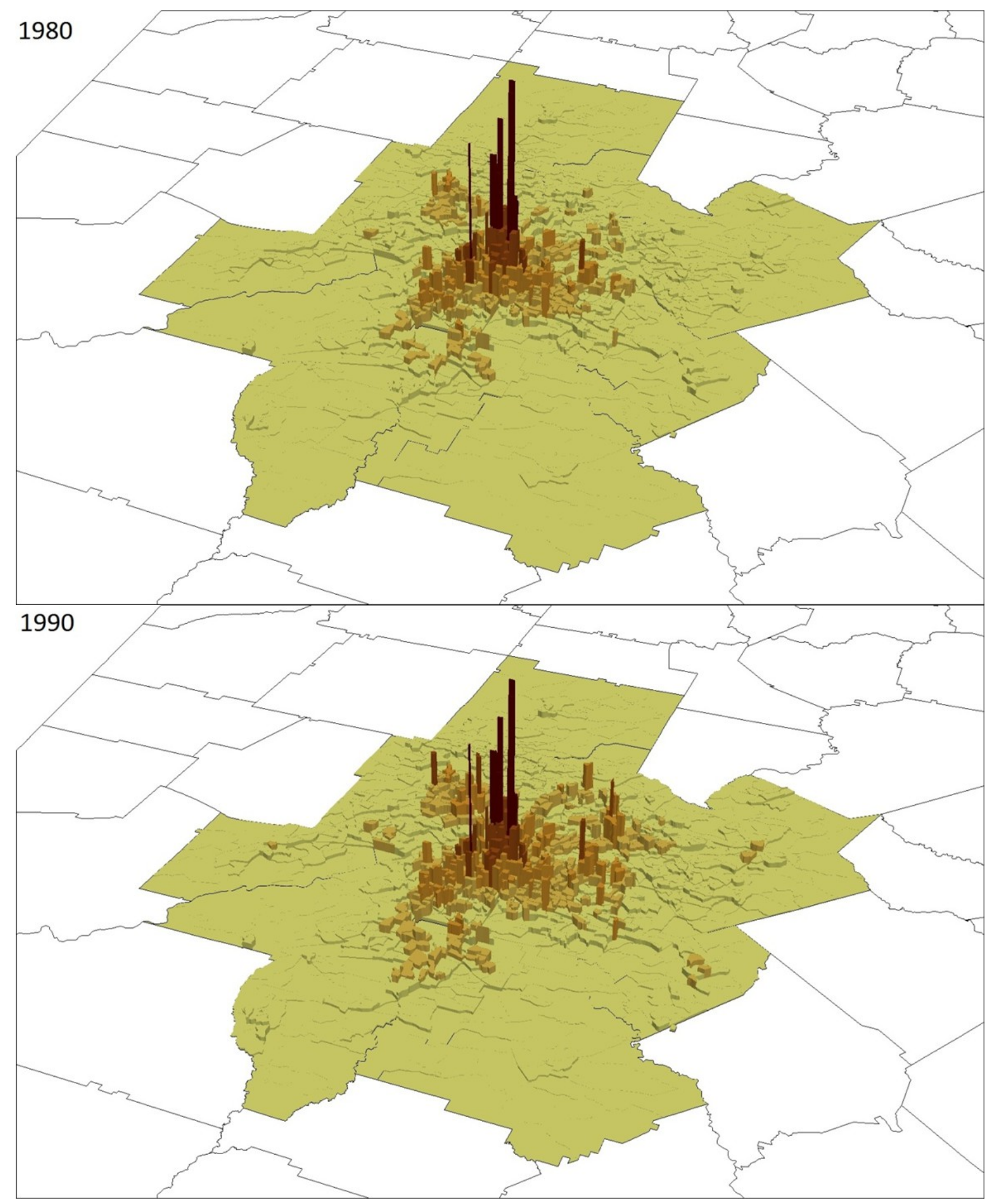




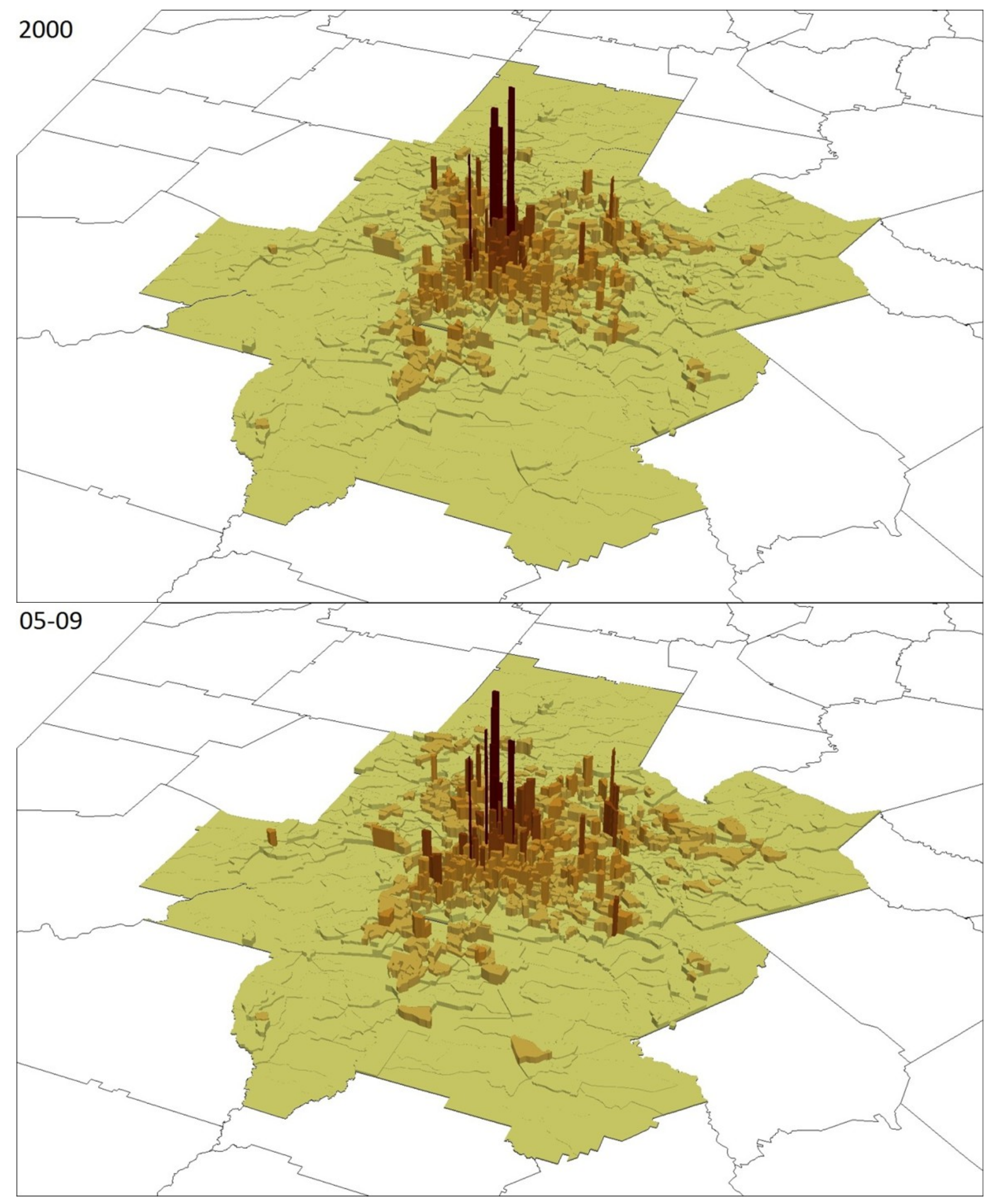

